Article

\title{
Limitations in the Grain Boundary Processing of the Recycled HDDR Nd-Fe-B System
}

\author{
Awais Ikram 1,2,3,*®i, Muhammad Awais ${ }^{4}\left(\mathbb{D}\right.$, Richard Sheridan ${ }^{4}$, Allan Walton ${ }^{4}$, \\ Spomenka Kobe ${ }^{2,3}$ (D), Franci Pušavec ${ }^{1}$ and Kristina Žužek Rožman ${ }^{2,3}$ \\ 1 Faculty of Mechanical Engineering, University of Ljubljana, Aškerčeva cesta 6, SI-1000 Ljubljana, Slovenia; \\ franci.pusavec@fs.uni-li.si \\ 2 Department for Nanostructured Materials, Jožef Stefan Institute, Jamova 39, SI-1000 Ljubljana, Slovenia; \\ spomenka.kobe@ijs.si (S.K.); tina.zuzek@ijs.si (K.Ž.R.) \\ 3 Jožef Stefan International Postgraduate School, Jamova 39, SI-1000 Ljubljana, Slovenia \\ 4 School of Metallurgy and Materials, University of Birmingham, Edgbaston, Birmingham B15 2TT, UK; \\ m.awais@bham.ac.uk (M.A.); r.s.sheridan.1@bham.ac.uk (R.S.); a.walton@bham.ac.uk (A.W.) \\ * Correspondence: rana.awaisikram@yahoo.com
}

Received: 26 June 2020; Accepted: 5 August 2020; Published: 10 August 2020

\begin{abstract}
Fully dense spark plasma sintered recycled and fresh HDDR Nd-Fe-B nanocrystalline bulk magnets were processed by surface grain boundary diffusion (GBD) treatment to further augment the coercivity and investigate the underlying diffusion mechanism. The fully dense SPS processed HDDR based magnets were placed in a crucible with varying the eutectic alloys $\operatorname{Pr}_{68} \mathrm{Cu}_{32}$ and $\mathrm{Dy}_{70} \mathrm{Cu}_{30}$ at 2-20 wt. \% as direct diffusion source above the ternary transition temperature for GBD processing followed by secondary annealing. The changes in mass gain was analyzed and weighted against the magnetic properties. For the recycled magnet, the coercivity $\left(H_{C i}\right)$ values obtained after optimal GBDP yielded $\sim 60 \%$ higher than the starting recycled HDDR powder and $17.5 \%$ higher than the SPS-ed processed magnets. The fresh MF-15P HDDR Nd-Fe-B based magnets gained 25-36\% higher coercivities with Pr-Cu GBDP. The FEG-SEM investigation provided insight on the diffusion depth and EDXS analysis indicated the changes in matrix and intergranular phase composition within the diffusion zone. The mechanism of surface to grain boundary diffusion and the limitations to thorough grain boundary diffusion in the HDDR Nd-Fe-B based bulk magnets were detailed in this study.
\end{abstract}

Keywords: rare earth permanent magnets; $\mathrm{HDDR} \mathrm{Nd}_{2} \mathrm{Fe}_{14} \mathrm{~B}$; recycling; spark plasma sintering; grain boundary diffusion processing (GBDP); high coercivity

\section{Introduction}

The Nd-Fe-B based rare-earth permanent magnets (REPMs) possess great significance for microelectronics, data storage, electric motors and medical devices [1]. The grain size refinement has been theorized to improve the coercivity $\left(H_{C}\right)$, i.e. resistance to demagnetization in REPMs [2]. The hydrogenation-disproportionation-desorption-recombination (HDDR) is a well-established and greener route for developing anisotropic ultrafine grains $(\sim 400 \mathrm{~nm})$ with preferential easy-axis orientation [3]. The overall surge in production volume and application demand has necessitated the utilization of recycled REPMs into the industrial feedstocks [4,5]. The effectiveness of hydrogen gas towards decrepitating (HD) and disproportionation (HDDR) of the end-of-life rare-earth (RE) scrap has convincing been proven in previous studies [6-12]. Contrary to the theoretical models, the HDDR Nd-Fe-B system lacks high coercivity as a translation of high magnetocrystalline anisotropy $\left(\mu_{0} H_{a}\right)$ $\sim 7.2 \mathrm{~T}$ because of crystal structure inhomogeneities, grain morphology, surface defects, oxidation, nonferromagnetic grain boundaries and localized exchange interactions at the grain interfaces, 
which restrict their usability [13-17]. Therefore, rather confining the potential application of the recycled HDDR Nd-Fe-B powders to polymer bonded magnets only [15,18-20], we have recently demonstrated Spark Plasma Sintering (SPS) as a convenient method to practically fabricate bulk magnets with magnetic properties at par with the end-of-life sintered magnets [21-23] or commercial grade HDDR Nd-Fe-B powder [24]. Several researchers have further explored the possibilities of improving the coercivity in the HDDR Nd-Fe-B system, with alloying additions [25-29], by mechanical milling [30-34] and via tailoring the disproportionation-desorption-recombination parameters [10,11,35-41].

More pragmatic approach has been the application of grain boundary diffusion (GBD) treatment on the HDDR Nd-Fe-B powders [36,42,43]. In case of the bulk magnets obtained via hot-pressing the HDDR Nd-Fe-B powder Song et al. [43] achieved $\mu_{0} H_{C}=1.55 \mathrm{~T}\left(H_{C i}=1230 \mathrm{kA} / \mathrm{m}\right)$ by eutectic Pr-Cu GBD treatment. Another versatile method applied to the bulk sintered magnets from the HDDR Nd-Fe-B powder has demonstrated that by doping with the rare-earth $(\mathrm{RE})$ fluoride $\left(\mathrm{DyF}_{3}\right)$ and controlled heat treatment, an improvement of up to $70 \%$ in coercivity $\left(H_{C i}\right)$ can be accomplished [44]. As compared to the sintered magnets from microcrystalline jet-milled powders and the nanocrystalline hot-deformed melt-spun ribbons, the GBD process has not been extensively researched on the HDDR Nd-Fe-B system. Moreover, a step ahead, very limited published data is available on the bulk HDDR Nd-Fe-B magnets, let aside GBD processing. When comparing the existing scientific reports, the underlying mechanism of diffusion has been not interpreted either for the HDDR Nd-Fe-B system [36,42], and sparsely interlinked with hot deformed nanocrystalline and sintered Nd-Fe-B magnets [45-48]. Citing the GBDP of the HDDR Nd-Fe-B powder, the loose powder particles have a remarkably higher surface area as compared to bulk sintered magnets and therefore, the suggested improvement in coercivity is only due to the widening of intergranular boundaries along the $\mathrm{Nd}_{2} \mathrm{Fe}_{14} \mathrm{~B}$ grains which would effectively decouple the grains with a higher concentration of non-ferromagnetic elements in this spacer phase $[29,49]$. Accordingly, the diffusion mechanism is relatively straightforward for the loose HDDR powder particles undergoing GBD treatment, such that the liquid phase engulfs all the particles when 5-30 wt. \% RE-rich alloys are added and the short-range diffusion causes widening of grain boundary regions within individual particles $[36,42]$. On the contrary, when compacted to full density, the diffusion mechanism in the HDDR Nd-Fe-B system is not the same as the loose powder particles and must vary with the GBD processing parameters. The previous report on the hot deformed HDDR Nd-Fe-B bulk magnets does not compliment on the diffusion mechanism either and relates more to the improvement in magnetic properties after GBDP with hyper-eutectic $\operatorname{Pr}_{82} \mathrm{Cu}_{18}$ alloy [43]. The recycled HDDR powder when compacted with SPS contains particle boundaries within which the RE-rich phase is non-uniformly distributed before annealing. The RE-rich phase gets transported from the interparticle region to the grain boundaries during the annealing and as a result, the coercivity reportedly increased [22]. This non-uniform distribution of Nd-rich phase in the particle boundaries happened under intense uniaxial pressure in the SPS such that liquid phase was squeezed out of grain boundaries to the interparticle junctions, and as a result, the coercivity dropped because of localized exchange interactions within the adjoining $\mathrm{Nd}_{2} \mathrm{Fe}_{14} \mathrm{~B}$ grains. During annealing, this liquid phase is partially transported back towards the grain boundaries surrounding $\sim 400 \mathrm{~nm}$ sized $\mathrm{Nd}_{2} \mathrm{Fe}_{14} \mathrm{~B}$ matrix grains from these interparticle boundaries, as the system is equilibrated. When evaluated based on particle size, we were able to distinguish that for the smaller particle $(<100 \mu \mathrm{m})$ there is a loss in total grain boundary area which also consequently resulted in a higher degree of oxidation as the liquid phase was squeezed out to the particle boundaries during SPS, where the bulk of hcp- $\mathrm{Nd}_{2} \mathrm{O}_{3}$ phase transformation took place [21]. The capillary transport was theorized and confirmed during the local doping and grain boundary engineering of bulk HDDR Nd-Fe-B magnets with $\mathrm{DyF}_{3}$ nanoparticles [44].

Evidently the insufficient understanding of the demagnetization (or coercivity) mechanism, the obvious effect of RE-rich interfaces-the grain boundaries as well as the surface diffusion kinetics in the HDDR Nd-Fe-B system potentially constrain their commercial applicability $[2,14,42,49-53]$.

The rudimentary aim of this scientific briefing is to highlight the potential challenges in grain boundary diffusion processing (GBDP) of the recycled HDDR Nd-Fe-B based fully dense bulk magnets 
in comparison to the commercial (Aichi MF-15P) HDDR powder with respect to the magnetic properties evolution after the GBD treatment with Pr-Cu and Dy-Cu eutectic alloys. In case of direct diffusion source and surface GBDP, the uniform and thorough dispersal of the RE-rich liquid phase to the grain boundaries under enhanced capillary transport was observed to be constricted in the bulk HDDR Nd-Fe-B magnets and this phenomenon has not been previously identified or reported elsewhere. Moreover, the diffusion depth after the thermal treatments and the effect of processing temperatures have been investigated in this report. This research also highlights the surface diffusion mechanism in the recycled HDDR Nd-Fe-B system from direct diffusion source, which has not been previously reported and interlink has been devised from the context of mass gain with the different GBDP parameters. The fundamental challenge regarding the diffusion depth limitations in the HDDR Nd-Fe-B bulk magnets has been investigated and proposed due to partial capillary diffusion confined due to the presence of complex intergranular oxides with the aid of SEM and EDXS analysis. Apart from the complicated diffusion mechanism in the HDDR Nd-Fe-B bulk magnets, the asymmetrical transformation of $(\mathrm{Pr}, \mathrm{Nd})_{2} \mathrm{Fe}_{14} \mathrm{~B}$ phase facets along with the interconnected $\mathrm{Pr}-\mathrm{Cu}$ rich liquid phase and the $(\mathrm{Pr}, \mathrm{Nd})_{X} \mathrm{CuO}_{Y}$ complexes at the intergranular junction have been suggested in correlation with the different GBDP parameters.

\section{Contribution to the Field Statement}

The majority of work on GBDP of Nd-Fe-B system accounts to sintered magnets from the microcrystalline powders and the nanocrystalline melt-spun ribbons, either in form of milled powder or hot-deformed magnets. On the contrary, citable literature on the Hydrogenation-Disproportionation-Desorption-Recombination (HDDR) Nd-Fe-B system is scarce such that these two nanocrystalline Nd-Fe-B systems are radically different and the diffusion treatment mechanism is relatively sparsely understood for the HDDR system. Importantly, the direct magnet recycling philosophy utilizes processing magnetic scrap with hydrogen, like in hydrogen decrepitation (HD) or HDDR, with latter technique extensively applicable for producing anisotropic $\leq 400 \mathrm{~nm}$ nanostructured $\mathrm{Nd}_{2} \mathrm{Fe}_{14} \mathrm{~B}$ grains and high coercivity bonded magnets. The GBDP on the HDDR powders have been reported [36,42] citing coercivity improvement but without the explanation of the diffusion mechanism in comparison to the sintered magnets or the nanocrystalline melt-spun ribbons. A recent study suggested application of $\mathrm{Pr}-\mathrm{Cu}$ low melting alloy to HDDR powder treated with hot deformation, improving the coercivity from $1065 \mathrm{kA} / \mathrm{m}$ to $1232 \mathrm{kA} / \mathrm{m}$ [43]. However, the bulk diffusion depths and the mechanism of the particle to grain boundary diffusion were still lacking.

The concurrent research work addresses the diffusion mechanism in the recycled HDDR Nd-Fe-B system, which has never been reported before. The details are presented in the context of mass gain with diffusion processing parameters and the diffusion depth limitations in the system due to limited capillary channelling and presence of complex intergranular oxides with the aid of SEM and EDXS analysis. Beyond the complications of constricted diffusion depth in the dense HDDR Nd-Fe-B bulk magnets, the asymmetrical formation of $(\mathrm{Pr}, \mathrm{Nd})_{2} \mathrm{Fe}_{14} \mathrm{~B}$ phase along the facets rich with $\mathrm{Pr}-\mathrm{Cu}$ containing liquid phase and $(\mathrm{Pr}, \mathrm{Nd})_{X} \mathrm{CuO}_{Y}$ phase transformation at the intergranular junction under different processing conditions have been identified. The magnetic properties as a comparison were also analysed after the diffusion treatment on the commercial HDDR Nd-Fe-B based bulk magnets, which resulted in $\sim 25 \%$ coercivity grain whereas the reprocessed magnets yielded $\sim 60 \%$ higher coercivity over the starting recycled HDDR powder. This brief report also indicates further action plans for the future on GBDP of the HDDR Nd-Fe-B system to tackle the limitations in diffusion depth and augment the coercivity beyond the current state of the art values.

\section{Materials and Methods}

The cylindrical/disk-shaped bulk SPS reprocessed magnets of diameter $9.5 \mathrm{~mm}$ and height $3 \mathrm{~mm}$ were prepared from the recycled HDDR Nd-Fe-B powder of nominal atomic composition: $\mathrm{Nd}_{13.4} \mathrm{Dy}_{0.67} \mathrm{Fe}_{78.6} \mathrm{~B}_{6.19} \mathrm{Nb}_{0.43} \mathrm{Al}_{0.72}$ (and in the mass ratio: $\mathrm{Nd}_{29.46} \mathrm{Dy}_{1.66} \mathrm{Fe}_{66.94} \mathrm{~B}_{1.02} \mathrm{Nb}_{0.65} \mathrm{Al}_{0.30}$ ). 
The HDDR processing on the end-of-life magnets with this composition has been well documented by Sheridan et al. $[10,54]$. Sequentially, the fabrication of bulk sintered magnets from the recycled HDDR Nd-Fe-B powder has also been thoroughly elaborated previously by Ikram et al. [21,22], including the physical properties like density $\left(7.57 \mathrm{~g} / \mathrm{cm}^{3}\right)$, oxygen content $(4800 \mathrm{ppm})$ and anisotropic powder particles in a wide distribution from 30-700 $\mu \mathrm{m}$ (average size $\sim 220 \mu \mathrm{m}$ ). As a comparison, the commercial grade Aichi's Magfine MF-15P HDDR Nd-Fe-B anisotropic powder (Aichi-ken, Japan), with average particle size $120 \mu \mathrm{m}$ in a narrow size distribution was also consolidated with the similar SPS processing conditions [23] to replicate the GBD effect on fresh material. The binary eutectic $\operatorname{Pr}_{68} \mathrm{Cu}_{32}$ and $\mathrm{Dy}_{70} \mathrm{Cu}_{30}$ alloy ribbons were prepared through arc-melting $10 \mathrm{~g}$ of elements in stoichiometric compositions (MAM-1 Arc Melter, Edmund Bühler, Bodelshausen, Germany). The Pr-Cu and Dy-Cu alloys were homogenized by 5 arc-melting passes and cooled to room temperature before grindings off the surfaces with 500 grit $\mathrm{SiC}$ papers. This was followed by vacuum induction melting $\left(>10^{-4} \mathrm{mbar}\right)$ and subsequent melt spinning on a $200 \mathrm{~mm}$ copper wheel with rotational velocity of $30 \mathrm{~m} / \mathrm{s}$ in argon atmosphere (MSP-10 SC Melt Spinner, Edmund Bühler, Bodelshausen, Germany). The alloy ribbons (several mm thickness, without further comminution) were placed within a ceramic crucible as direct diffusion source on the top and bottom of surface cleaned bulk magnets (thermally annealed at $750{ }^{\circ} \mathrm{C}$ for $1 \mathrm{~h}$ ) [21]. The loaded crucible was placed in a horizontal tube furnace (Carbolite Gero Limited, Hope Valley, UK) for the GBD processing in high vacuum $\left(>10^{-5} \mathrm{mbar}\right)$ with a heating rate of $50{ }^{\circ} \mathrm{C} / \mathrm{min}$. The GBD treatment was performed at $900{ }^{\circ} \mathrm{C}$ for $3 \mathrm{~h}$ with secondary annealing at $500{ }^{\circ} \mathrm{C}$ for additional $3 \mathrm{~h}$ in the same tube furnace setup (vacuum and heating rate), which is above the ternary transition temperature [22] to accelerate the surface diffusivity. The magnetic measurements on bulk GBDP samples were performed at room temperature on a permeameter (Magnet-Physik Dr. Steingroever, Cologne, Germany) with demagnetizing fields up to 2 T. For further characterization, the samples were thermally demagnetized at $400^{\circ} \mathrm{C}$ for $15 \mathrm{~min}$ in the tube furnace (vacuum $>10^{-5} \mathrm{mbar}$ ). Samples were sliced into half by low speed diamond saw at $300 \mathrm{rpm}$ and fluxed with isopropanol (IsoMet ${ }^{\mathrm{TM}}$ Precision Cutter, Buehler, IL, USA). Later, these demagnetized GBDP samples were grinded by 500,1000 and 2400 grit size $\mathrm{SiC}$ papers. Successively, the polishing was done with $0.25 \mu \mathrm{m}$ diamond paste slurry on a velvet cloth at $200 \mathrm{rpm}$. The microstructural investigation was accomplished with JEOL 7600F (Field Emission Scanning Electron Microscope-JEOL Ltd., Tokyo, Japan) with an electron energy dispersive X-ray spectroscopy (EDXS) analyzer and a $20 \mathrm{~mm}^{2}$ Oxford INCA 350 detector (Oxford Instruments, High Wycombe, UK) for compositional/elemental analysis, performed at $20 \mathrm{keV}$ accelerating voltage.

\section{Results and Discussion}

The recycled and fresh Magfine MF-15 HDDR Nd-Fe-B magnets were developed by SPS sintering operation at $750^{\circ} \mathrm{C}$ with holding time of 1 minute, and further complemented by thermal treatment at $750{ }^{\circ} \mathrm{C}$ for $1 \mathrm{~h}$. The magnetic properties of HDDR powder and annealed bulk magnets were measured prior to the GBD treatment with eutectic Pr-Cu and Dy-Cu alloy ribbons and summarized in Table 1 [22].

Table 1. Magnetic properties of HDDR Nd-Fe-B magnets prior to Pr-Cu and Dy-Cu GBDP.

\begin{tabular}{|c|c|c|c|c|}
\hline Material Class & Coercivity $H_{C i}(\mathrm{kA} / \mathrm{m})$ & Remanence $B_{r}(\mathrm{~T})$ & $B H_{\max }\left(\mathrm{kJ} / \mathrm{m}^{3}\right)$ & $M_{r} / M_{S}$ Ratio \\
\hline End-of-Life (EOL) Scrap Magnet & 1170 & 1.19 & 250 & 0.74 \\
\hline Recycled HDDR Nd-Fe-B Powder (RP) & 830 & 0.9 & 124 & 0.56 \\
\hline $\begin{array}{c}\text { Optimally SPS-ed and Annealed Recycled } \\
\text { Magnets (RMs) }\end{array}$ & $1150-1170$ & $0.79-0.83$ & $112-120$ & 0.52 \\
\hline $\begin{array}{c}\text { Fresh Magfine MF-15P HDDR Nd-Fe-B } \\
\text { Powder (MFP) }\end{array}$ & $1020-1130$ & $1.27-1.32$ & $270-310$ & $>0.81$ \\
\hline $\begin{array}{c}\text { Optimally SPS-ed and Annealed Fresh MF-15P } \\
\text { Magnets (MFMs), see Section } 4.3\end{array}$ & $960-970$ & $1.06-1.07$ & $196-200$ & 0.67 \\
\hline
\end{tabular}




\subsection{Dy-Cu Grain Boundary Diffusion Treatment}

The grain boundary diffusion (GBD) treatment parameters were contemplated from a similar study on Nd-Fe-B melt-spun ribbons by Bao et al. [46] in which $\mathrm{Dy}_{70} \mathrm{Cu}_{30}$ and $\operatorname{Pr}_{68} \mathrm{Cu}_{32}$ were utilized. The starting bulk magnets had a relative density $>99 \%$ after the thermal treatment, therefore they can be classified as fully dense magnets before GBDP. The eutectic melting point for $\mathrm{Dy}_{70} \mathrm{Cu}_{30}$ was reported as $790{ }^{\circ} \mathrm{C}$. In order to promote eutectic alloy ribbons fluidity and uniform melting on the surfaces of bulk magnets, the primary GBDP temperature was retained at $900{ }^{\circ} \mathrm{C}$ for $3 \mathrm{~h}$. Secondary annealing at $500{ }^{\circ} \mathrm{C}$ for $3 \mathrm{~h}$ was opted to relax the thermal strains formed in the bulk magnets during GBDP. The mass gain (up to 3 digits precision) was analyzed to overview how much the molten species have diffused into the magnets after GBDP. The starting magnets ranged from 2.600-2.800 $\mathrm{g}$ in nominal masses after the initial grinding was performed to remove carbon layer off the SPS-ed specimen. The actual mass gain in reprocessed magnets (RMs) was as follows: for $2 \mathrm{wt} . \%$ sample approx. $0.019 \mathrm{~g}$ (1.94\%), $10 \mathrm{wt}$. \% sample approx. $0.068 \mathrm{~g}(2.57 \%)$ and $20 \mathrm{wt}$. \% sample approx. $0.0911 \mathrm{~g}(3.25 \%)$.

The augmentation of the magnetic properties is clearly illustrated in Figure 1 . The coercivity $\left(H_{C i}\right)$ of the starting bulk magnets $(1148 \mathrm{kA} / \mathrm{m})$ increased to a modest value of $1220 \mathrm{kA} / \mathrm{m}$ with $2 . w \mathrm{t}$. \% Dy-Cu eutectic alloy addition at the first stage of GBDP and slightly more to $1250 \mathrm{kA} / \mathrm{m}$ after secondary annealing at $500{ }^{\circ} \mathrm{C}$. In case of $10 \mathrm{wt}$. \% Dy-Cu alloy added as the diffusion source, $H_{C i}$ increased from $1141 \mathrm{kA} / \mathrm{m}$ to $1216 \mathrm{kA} / \mathrm{m}$ at $900{ }^{\circ} \mathrm{C}$ and finally to $1257 \mathrm{kA} / \mathrm{m}$ with the secondary annealing. For $20 \mathrm{wt}$ \% there was a subsequent increase in coercivity from $1149 \mathrm{kA} / \mathrm{m}$ to $1226 \mathrm{kA} / \mathrm{m}\left(\right.$ at $\left.900{ }^{\circ} \mathrm{C}\right)$ and $1287 \mathrm{kA} / \mathrm{m}$ (at $500{ }^{\circ} \mathrm{C}$ ), as shown in Figure 1a. Whereas the remanence $\left(B_{r}\right)$ of the starting bulk magnets prior to GBDP was uniformly $0.81 \mathrm{~T}$ and it consistently dropped more for primary diffusion processing at $900{ }^{\circ} \mathrm{C}$ with a minor recovery after secondary annealing at $500{ }^{\circ} \mathrm{C}$. Earlier investigation on hot-deformed HDDR Nd-Fe-B magnets suggested that the thermal treatment above the ternary transformation point introduces higher degree of alignment (texturing) and the subsequent relaxation in processing strains introduced by grain boundary phase [23]. This factor may be at play here such that the RE-enriched liquid phase at $900{ }^{\circ} \mathrm{C}$ realigns the HDDR particles slightly, since the melt-flows preferentially along the c-axis, resulting in a minor improvement in remanence after annealing [22]. The overall the drop in the $B_{r}$ due to a higher weight fraction of Dy-Cu alloy after the GBD treatment has been reported due to the antiferromagnetic coupling introduced by partial substitution of $\mathrm{Nd}$ with the Dy atoms [55] at the surface of the nanocrystalline $\mathrm{Nd}_{2} \mathrm{Fe}_{14} \mathrm{~B}$ matrix grains during the primary diffusion treatment at elevated temperatures, above the binary eutectic $790^{\circ} \mathrm{C}$ for $\mathrm{Dy}_{70} \mathrm{Cu}_{30}$ and ternary transition temperature of Nd-Fe-B alloys $\left(665^{\circ} \mathrm{C}\right)[44,46]$. This $20 \mathrm{wt}$. \% addition of Dy-Cu eutectic ribbons caused approximately $55 \%$ improvement in $\mathrm{H}_{\mathrm{Ci}}$ over the starting recycled HDDR Nd-Fe-B powder and $12 \%$ better demagnetization resistance over the optimally SPS reprocessed bulk magnets. Comparing the gain in masses after GBDP, the surface of RMs still contained brazed and non-diffused species on the top and bottom, so the surface was grinded to the original height of the bulk magnet for magnetic measurements. This partial mass gain, besides very slight decline in the $B_{r}(<0.1 \mathrm{~T})$ for the diffusing Dy indicates that the Dy-Cu alloy ribbons did not melt properly under the $900{ }^{\circ} \mathrm{C}$ GBDP conditions, owing to their high eutectic temperature which caused very limited $\mathrm{H}_{\mathrm{Ci}}$ improvement in RMs.

\subsection{Pr-Cu Grain Boundary Diffusion Treatment}

The eutectic melting regime for $\operatorname{Pr}_{68} \mathrm{Cu}_{32}$ based melt-spun ribbons was identified at $472{ }^{\circ} \mathrm{C}$, in which the authors also suggested Pr-Cu alloys were found more effective than Dy-Cu system to augment the coercivity, without conversely affecting the remanent magnetization [46]. The change in relative density was insignificant after the GBDP of reprocessed magnets (RMs) and values were consistently higher than $7.56 \mathrm{~g} / \mathrm{cm}^{3}$ after primary diffusion treatment and secondary annealing. The actual mass gain in Pr-Cu GBDP reprocessed magnets (RMs) was higher as compared to the Dy-Cu based RMs, with measurements detailed as follows: for $2 \mathrm{wt}$. \% sample approx. $0.055 \mathrm{~g}(2 \%), 10 \mathrm{wt}$. \% sample approx. $0.105 \mathrm{~g}(3.87 \%)$ and $20 \mathrm{wt}$. \% sample approx. $0.138 \mathrm{~g}$ (4.96\%). Apparently the Pr-Cu 
alloy diffused from the surface in $2 \mathrm{wt}$. \% condition, the brazed species were still present in 10 and 20 wt. \% RM samples which were finely grinded to the preceding dimensions.
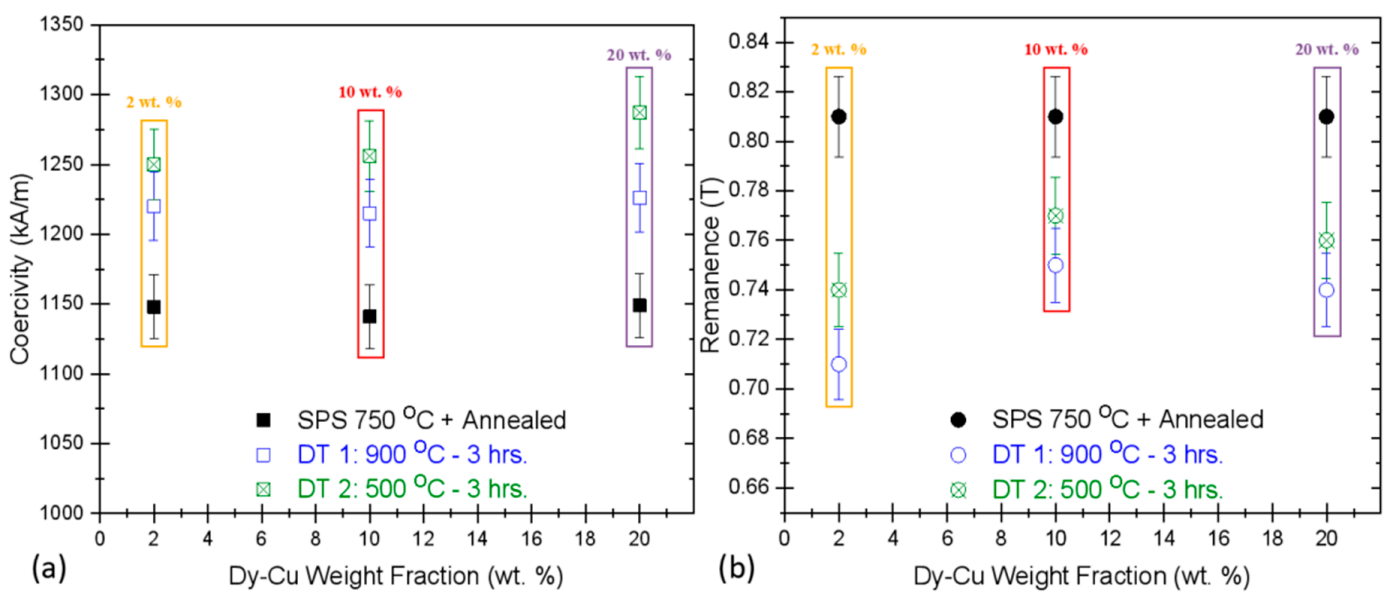

Figure 1. (a) Dependence of coercivity $\left(H_{C i}\right)$ and $(\mathbf{b})$ remanence $\left(B_{r}\right)$ with different weight fractions of eutectic $\mathrm{Dy}_{70} \mathrm{Cu}_{30}$ alloys during the two stages of GBD treatment. Plots legend: yellow 2 wt. \%, red $10 \mathrm{wt}$. \% and purple $20 \mathrm{wt}$. \% Dy-Cu as the diffusion source on bulk SPS reprocessed magnets (RMs).

The magnetic properties prior to and after the GBDP are illustrated in Figure 2, indicating a more profound effect of $\mathrm{Pr}-\mathrm{Cu}$ alloy in improving the coercivity without appreciable reduction in the remanent magnetization. For $2 \mathrm{wt}$. \% Pr-Cu ribbons, a minor improvement in $H_{C i}=1221 \mathrm{kA} / \mathrm{m}$ was observed $\left(\mathrm{RM} H_{\mathrm{C} i}=1157 \mathrm{kA} / \mathrm{m}\right)$ during primary diffusion which further increased to 1283 $\mathrm{kA} / \mathrm{m}$ after annealing, as shown in Figure 2a. This value corresponds to similar $H_{C i}$ improvement as possible with $20 \mathrm{wt}$. \% Dy-Cu alloy (actual $3.25 \%$ mass gain). The $B_{r}$ improved slightly to $0.82 \mathrm{~T}$ over the original starting RM $(0.8 \mathrm{~T})$ after $2 \mathrm{wt}$. \% GBDP, which indicates Pr diffusion is overall more efficient in augmenting the $H_{C i}$ without negatively impacting the $B_{r}$ as in case of Dy diffusion. The $B_{r}$ dropped slightly to $0.78 \mathrm{~T}(10 \mathrm{wt.} \%)$ and $0.75 \mathrm{~T}(20 \mathrm{wt}$. \%) Pr-Cu GBDP, as shown in Figure $2 \mathrm{~b}$ indicating the dilution of the hard-magnetic $\mathrm{Nd}_{2} \mathrm{Fe}_{14} \mathrm{~B}$ phase with the non-ferromagnetic species diffusing inwards from the surface $[45-47,56,57]$. Consequently, with more mass gained by 10 and $20 \mathrm{wt}$. \% Pr-Cu samples, it is plausible that the remanent magnetization is expected to get reduced since these eutectic alloys are compensating and becoming part of the intergranular phase, making it richer with the REEs content. With more intergranular phase and unchanged volume fraction of the ferromagnetic phases, we can expect the improvement in coercivity but only at the cost of a slight reduction in remanence [2]. However, the toll on remanence with the addition of Pr-Cu alloys is comparatively less prominent as the Dy-Cu system, since the antiferromagnetic coupling of substituting the Dy atoms in the hard-ferromagnetic phases causes a more noticeable drop in the net magnetization [46], which is apparent from Figure 1. Comparatively the $H_{C i}$ improved from $1160 \mathrm{kA} / \mathrm{m}$ (RMs) to $1260 \mathrm{kA} / \mathrm{m}\left(900{ }^{\circ} \mathrm{C}\right.$ GBDP) and $1308 \mathrm{kA} / \mathrm{m}$ (after secondary annealing) for $10 \mathrm{wt}$ \% Pr-Cu diffusion processing ( $3.87 \%$ mass increase). Likewise, utilizing $20 \mathrm{wt}$. $\%$ (4.96\% actual mass gain) $\mathrm{Pr}-\mathrm{Cu}$ alloy ribbons as the direct diffusion source resulted in $H_{C i}$ enhancement to $1290 \mathrm{kA} / \mathrm{m}$ (just after primary diffusion treatment- $-900^{\circ} \mathrm{C}$ ) and subsequently to $1322 \mathrm{kA} / \mathrm{m}$ with additional annealing (at $500{ }^{\circ} \mathrm{C}$ ), as disclosed in Figure 2a. This approx. 5\% mass gain with $\mathrm{Pr}-\mathrm{Cu}$ diffusion treatment suggests $15 \%$ higher coercivity over the starting RM and 59.3\% over the original recycled HDDR Nd-Fe-B powder (RP). These attained values are slightly better than the recently reported $H_{C i}$ improvement by $\mathrm{Pr}-\mathrm{Cu}$ diffusion processing of the hot deformed magnets to $1232 \mathrm{kA} / \mathrm{m}$ from the fresh HDDR Nd-Fe-B powders, with starting $H_{C i}=1065 \mathrm{kA} / \mathrm{m}$ [43]. 

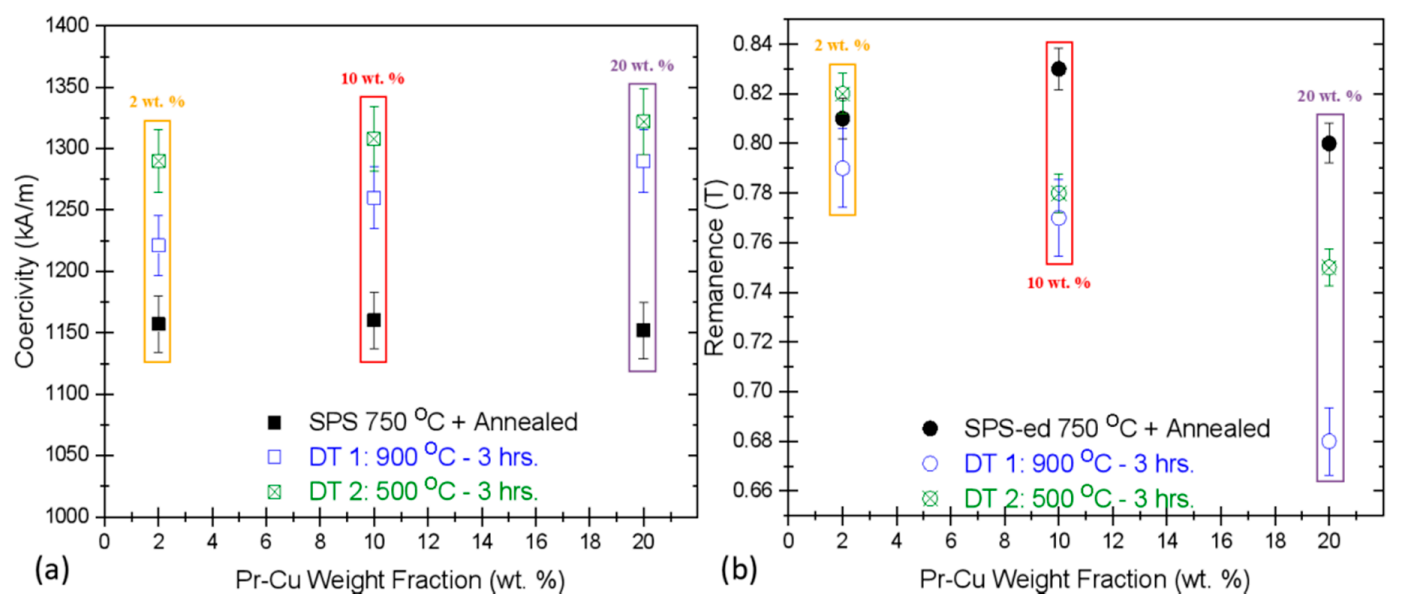

Figure 2. The variation of (a) coercivity $\left(H_{C i}\right)$ and $(\mathbf{b})$ remanence $\left(B_{r}\right)$ after GBD treatment with different wt. $\% \operatorname{Pr}_{68} \mathrm{Cu}_{32}$ alloy ribbons. Plots legend: yellow 2 wt. \%, red 10 wt. \% and purple 20 wt. \% Pr-Cu as the diffusion source on bulk HDDR Nd-Fe-B SPS-ed magnets (RM).

The microstructural analysis was performed on $2 \mathrm{wt}$. \% Pr-Cu diffusion processed RM after secondary annealing, using the backscattered electron imaging as shown in Figure 3. For the sake of comparison, the recycled HDDR powder (RP) and the reprocessed magnet (RM) prior to the GBDP with Pr-Cu alloys are also shown in Figure 3A,B respectively. Fractography of the HDDR powder particles will most inevitably reveal microstructure similar to Figure $3 \mathrm{~A}$, i.e. $3 \mathrm{D}$ network of $\mathrm{Nd}_{2} \mathrm{Fe}_{14} \mathrm{~B}$ grains with preferred orientation along the easy-axis (c-axis) in each particle. The disproportionation of microcrystalline $\mathrm{Nd}_{2} \mathrm{Fe}_{14} \mathrm{~B}$ matrix in the EOL magnets spreads uniformly at elevated temperatures to a reaction mixture of $\mathrm{NdH}_{2}, \alpha$-Fe and $\mathrm{Fe}_{2} \mathrm{~B}$ throughout the whole particle, such that the vacuum desorption of $\mathrm{H}_{2}$ and recombination reaction creates a transcending continuous 3D network of submicron sized $\mathrm{Nd}_{2} \mathrm{Fe}_{14} \mathrm{~B}$ grains within each HDDR particle [2]. As reported previously, the recycled HDDR Nd-Fe-B powder contains a high oxygen content ( $\sim 5000 \mathrm{ppm})$ and therefore formation of additional oxide phases (fcc-NdOX and cubic/hcp $\mathrm{Nd}_{2} \mathrm{O}_{3}$ - depending on oxygen concentration/up-take) reduces the overall amount of $\mathrm{Nd}$-rich phase present within the system below 13.4 at. \% [21,23]. The SPS reprocessed magnet (Figure 3B), has been developed with microstructure optimally retained conceivably as close as possible to the starting recycled powder and enhanced magnetic properties followed by annealing. The anticipated changes with GBD treatment are illustrated in Figure 3C-F for $2 \mathrm{wt}$ \% Pr-Cu surface diffusion after the primary and secondary annealing. This specimen was also selected for the reason that nearly all the $\mathrm{Pr}-\mathrm{Cu}$ alloy apparently diffused inside the magnet indicated by $2 \%$ weight gain. The BSE images indicates different zones of diffusion (bright phase indicates rare-earth rich phases) detailed in Figure 3C. The diffusion depth illustrated in this image is clearly limited as the $\mathrm{Pr}$ - $\mathrm{Cu}$-rich species were located in near surface regions, ranging up to approximately $250 \mu \mathrm{m}$ from the surface. The possible origin of extended diffusion zone must be associated with the primary GBD treatment at $900{ }^{\circ} \mathrm{C}$, such that it is anticipated that time and concentration dependent diffusion happened with the liquification of aggregate RE-phase above the ternary transition temperature $\left(665^{\circ} \mathrm{C}\right)$, which enhanced the diffusion depth to $\sim 600 \mu \mathrm{m}$ from the surface. This lack of diffusion depth beyond $\sim 600 \mu \mathrm{m}$ can be assumed because of high surface tension caused by the eutectic melt-pool, which requires multiple micron sized channels to diffuse through the surface regions; besides time and concentration gradient limitations at the surface. As previously demonstrated, the HDDR Nd-Fe-B system is very much unlike the melt-spun ribbon flakes and the sintered magnets with several micron sized grains having thicker grain boundary channels, such that the RE-rich melt is transported thermodynamically by grain boundary channels. In this HDDR Nd-Fe-B system, the diffusive transport happens via inwards capillary suction along very thin grain boundary channels of $\sim 3 \mathrm{~nm}$ thickness [44]. This complicates the diffusivity and the prodigious surface tension caused by a high mass fraction 
of eutectic species in nearly dense magnets require a greater number of surface perforations to penetrate inwards. Thinner channels in the HDDR Nd-Fe-B surges the required capillary forces for diffusivity towards the grain boundaries connecting the nanocrystalline grains. The perforations in the conventional sintered magnets from microcrystalline precursors are considerably thicker to promote grain boundary diffusion. The HDDR particle size is $\sim 220 \mu \mathrm{m}$, whereas in the sintered magnets the particle size is around 5-10 $\mu \mathrm{m}$, which indicates numerous grain boundary channels in the sintered magnets as compared to the particle boundaries accessible at the surface of HDDR Nd-Fe-B based magnets. The nanoscopic grain boundary channels connected to the particle boundaries in the HDDR Nd-Fe-B system are much thinner than the sintered magnets, in which diffusion is controlled by concentration gradient $[46,55]$. The first hindrance for the RE-rich liquid phase are the surface channels to diffuse the liquid phase along the particle boundaries, which in turn distribute this liquid phase along the grain boundaries under capillary diffusion [44]. Hence the effective particle boundary surface area in the HDDR Nd-Fe-B system is considerably lower than the sintered magnets, which is required to accelerate the diffusion from the surface region under capillary forces and so the diffusion depth is lower than $1 \mathrm{~mm}$. Another factor to account for the partial diffusivity is related to preferential flow kinetics with the magnetization easy axis (c-axis) in the HDDR Nd-Fe-B system [23]. In case of GBD processing of bulk magnets, the powder particles are joined up with interparticle boundaries, such that for these regions oriented with (parallel to) the easy axis (c-axis) will tend to preferentially allow capillary diffusion in to the grain boundary channels adjoining the ultrafine $\mathrm{Nd}_{2} \mathrm{Fe}_{14} \mathrm{~B}$ grains within the diffusion (Figure 3D) and extended zones (Figure 3E), in the vicinity of Pr-Cu rich pools at the intergranular junctions. The presence of darker features $100-200 \mu \mathrm{m}$ in size from Figure 3C are merely powder particles misoriented during the SPS reprocessing under applied pressures [22].

The Pr-Cu diffusion treatment has already been reported that the Pr-rich liquid/intergranular phase induces strains in the $\mathrm{Nd}_{2} \mathrm{Fe}_{14} \mathrm{~B}$ matrix phase which may also lead to strain-induced transformation of $\mathrm{Nd}_{2} \mathrm{O}_{3}$ above ternary point facilitated by $\mathrm{Cu}$ segregation [58]. Therefore, the secondary annealing at $500{ }^{\circ} \mathrm{C}$ helps in relaxing the microstructure with reduced defect density by smoothening the grain boundaries and reprecipitated $(\mathrm{Pr}, \mathrm{Nd})_{2} \mathrm{Fe}_{14} \mathrm{~B}$ surfaces from the RE-enriched melt, which is beneficial for the improvement in the magnetic properties. Close-up image of diffusion zone is shown in Figure 3D, which indicates the various phases randomly distributed within the microstructure and quantified in Table 2. This region is concentrated with Pr-rich phases, with a high-volume fraction of bright regions corresponding to $(\mathrm{Pr}, \mathrm{Nd}) \mathrm{O}_{\mathrm{X}}$ type species intercalated at the HDDR particle boundaries and the $\mathrm{Nd}_{2} \mathrm{Fe}_{14} \mathrm{~B}$ intergranular regions. In the near surface regions up to extended diffusion zone and close to the Pr-rich phase, the stoichiometric composition of the matrix phase resembled $(\mathrm{Pr}, \mathrm{Nd})_{2} \mathrm{Fe}_{14} \mathrm{~B}$ [28]. The surface of 2:14:1 grains partially melt during GBDP above ternary transition temperature in equilibrium with RE-rich phase, such that enrichment of facet region causes reprecipitation and asymmetrical solidification of shell structure at the interface (in case of HREEs) [55]. Previously it has been suggested that the grains facets in contact with $(\mathrm{Nd}, \mathrm{Pr})$-rich liquid phase transformed to $(\mathrm{Pr}, \mathrm{Nd})_{2} \mathrm{Fe}_{14} \mathrm{~B}$ due to $\mathrm{Nd}$ depletion but did not completely form the Pr-type shell structure over the $\mathrm{Nd}_{2} \mathrm{Fe}_{14} \mathrm{~B}$ grains [58]. The EDXS results provide evidence for this transformation of nanocrystalline matrix grains during GBDP, such that the surfaces connected to the Pr-enriched liquid phase partially substitute $\mathrm{Nd}$ with $\mathrm{Pr}$ to form $(\mathrm{Pr}, \mathrm{Nd})_{2} \mathrm{Fe}_{14} \mathrm{~B}$ facets and depleted $\mathrm{Nd}$ becomes part of liquid phase. In the diffusion region, the Pr-rich phase was analyzed with a nominal composition of $(\mathrm{Pr}, \mathrm{Nd}) \mathrm{O}_{2}$, besides the presence of slightly greyish $\mathrm{Pr}_{2} \mathrm{O}_{3} / \mathrm{Nd}_{2} \mathrm{O}_{3}$ oxide phase which is formed due to excessive availability of oxygen within the microstructure. Overall, the distribution of $\mathrm{Pr}, \mathrm{Nd}, \mathrm{Cu}$ and $\mathrm{O}$ at the intergranular channels with matrix phase and the particle boundaries is non-uniform and varies inconsistently with the diffusion depth. Furthermore it can also be hypothesized that the secondary annealing may not have contributed significantly in increasing the diffusion depth of RE-rich species, since the Pr-Cu alloy should have transformed to different phases as indicated in Figure 3D above the ternary transition temperature during the primary GBDP. 


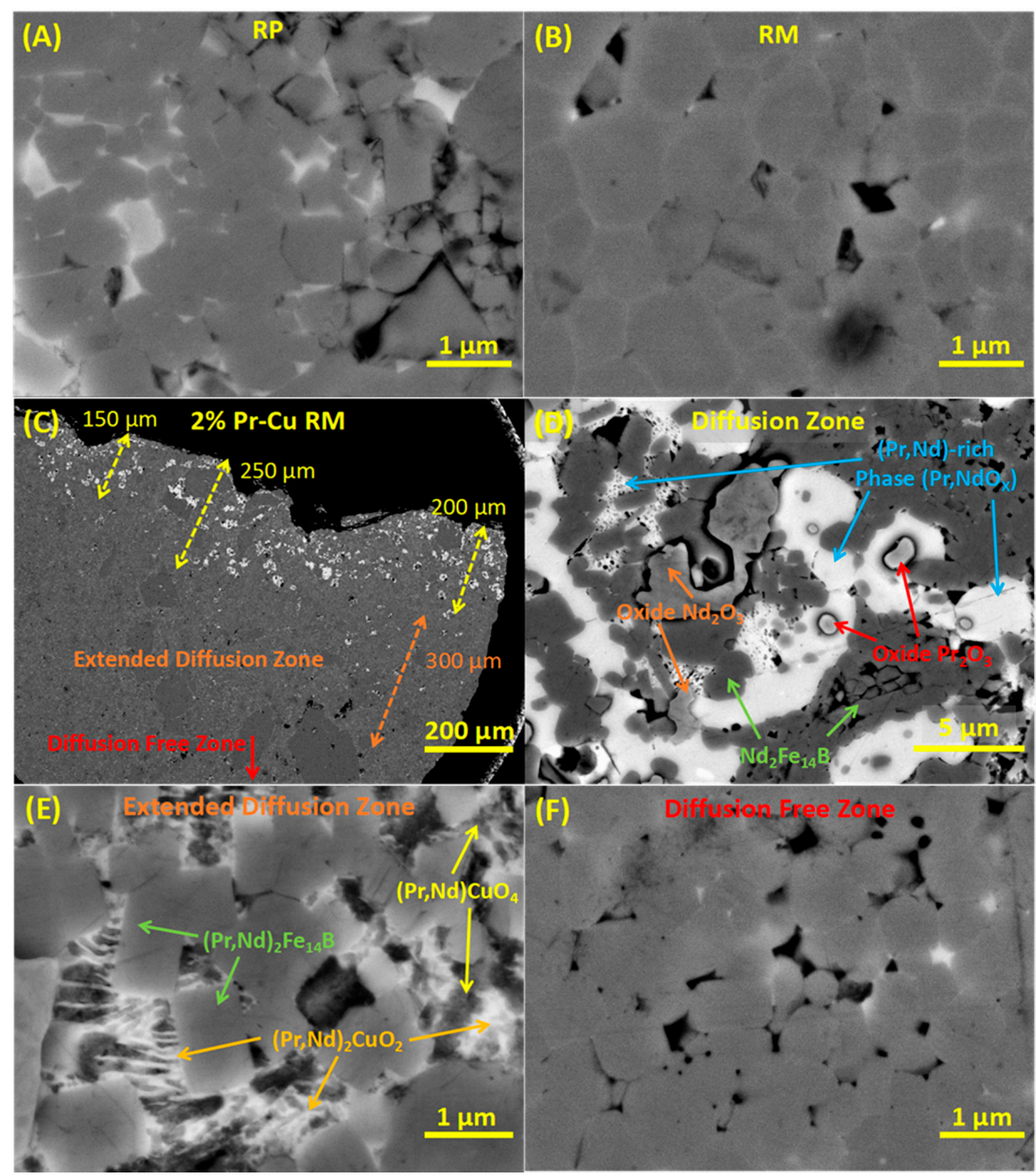

Figure 3. BSE-SEM analysis, high magnification image of: (A) bonded recycled HDDR Nd-Fe-B powder (RP); (B) optimally SPS-ed HDDR Nd-Fe-B bulk magnet (RM) prior to GBDP; (C) micrograph of 2 wt. \% Pr-Cu GBDP specimen indicating diffusion zones after secondary annealing; (D) close-up image of diffusion zone with different phases quantified in Table 2; (E) the diffusion zone extension due to secondary annealing showing the distribution of Pr-Cu-rich phase at the intergranular regions; and $(\mathbf{F})$ diffusion free zone which mimics the microstructure of original RM due to limited diffusion depth of Pr-Cu alloys in HDDR Nd-Fe-B system.

The miscibility of eutectic species in the Nd-rich intergranular phase is significantly higher and therefore, for the surface species to be propelled inside, rate of mass transport (diffusivity) is limited by concentration gradient which is also limited by time. Hence during the primary GBD treatment, it is anticipated that the diffusivity limits the penetration of melt to near surface regions only (up to 500-600 $\mu \mathrm{m})$. Since the primary GBDP occurs above the ternary eutectic point $\left(665^{\circ} \mathrm{C}\right)$, so the Nd-rich phase is in liquid state with nanocrystalline $\mathrm{Nd}_{2} \mathrm{Fe}_{14} \mathrm{~B}$ and $\mathrm{Nd}_{1+\varepsilon} \mathrm{Fe}_{4} \mathrm{~B}_{4}$ phases [22]. Now the influx and dissolution of Pr-Cu will be limited by the concentration gradient of liquid phase along the HDDR particle boundaries before capillary infusion along the nanocrystalline grains. Initially $\operatorname{Pr}$ and $\mathrm{Cu}$ in the RE-rich melt become part of aggregate liquid phase at the particle boundaries making it enriched with the rare-earth species. As the capillary diffusion begins, $\mathrm{Cu}$ remains segregated within the liquid phase while Pr substitutes partially on the facets in contact with RE-rich liquid phase [43]. This capillary diffusion from the surface to particle boundaries and finally to grain boundaries is both time and 
concentration dependent, although considerably slow as compared to the localized diffusion previously devised by $\mathrm{DyF}_{3}$ doping of the HDDR Nd-Fe-B system [44]. The diffusion zone, shown in Figure 3D also indicates the presence of secondary phases like $\mathrm{Nd}_{2} \mathrm{O}_{3}$ at the intergranular junctions restrict the capillary flow of liquid phase, either by limiting the liquidus phase to localized regions only and/or scavenging the rare earth elements to form more dhcp- $\mathrm{RE}_{2} \mathrm{O}_{3}$ type phases [22]. Since EDXS indicates a more common distribution of $\mathrm{Nd}_{2} \mathrm{O}_{3}$ phase as compared to $\operatorname{Pr}_{2} \mathrm{O}_{3}$, which implies that Pr preferably interacts more with the surface facets of adjacent $\mathrm{Nd}_{2} \mathrm{Fe}_{14} \mathrm{~B}$ grains or remain associated within the grain boundary channels. The segregation of $\mathrm{Cu}$ in the intergranular region has been observed to rearrange the $\mathrm{Nd}$ atoms during annealing at $500{ }^{\circ} \mathrm{C}$, resulting into transformation of hcp- $\mathrm{Nd}_{2} \mathrm{O}_{3}$ oxide to cubic- $\mathrm{Nd}_{2} \mathrm{O}_{3}$ phase $[43,59]$. This suggests that $\mathrm{Cu}$ segregation induced changes to the hcp- $\mathrm{Nd}_{2} \mathrm{O}_{3}$ phase at the intergranular region favors the transformation to cubic type crystal structure, which releases the strain introduced by hcp- $\mathrm{Nd}_{2} \mathrm{O}_{3}$ phase due to their significantly higher mismatch with the $(\mathrm{Pr}, \mathrm{Nd})_{2} \mathrm{Fe}_{14} \mathrm{~B}$ matrix grains [21]. Furthermore, the transformation of cubic- $\mathrm{Nd}_{2} \mathrm{O}_{3}$ phase originates from the oxidation of metallic $\mathrm{Nd}$ and cubic $-\mathrm{PrO}_{2}$ type phase stabilized by $\mathrm{Cu}$ at the intergranular junctions [43]. Additionally, the RE-rich phase has been identified within the diffusion zone in $\mathrm{RE}^{-\mathrm{O}_{X}}$ form, suggesting the bright region is composed of $(\mathrm{Pr}, \mathrm{Nd}) \mathrm{O}_{\mathrm{X}}$ phase. The more lamellar form factor indicates $\mathrm{NdO}_{2} / \mathrm{NdO}$ type phase in the vicinity to $(\mathrm{Pr}, \mathrm{Nd})_{2} \mathrm{Fe}_{14} \mathrm{~B}$ matrix, while the continuous white region suggests combined $\mathrm{NdO}_{2}$ and $(\mathrm{Pr}, \mathrm{Nd}) \mathrm{O}_{2}$ phase. More elaborate analytical analysis with the transmission electron microscopy to understand the capillary diffusion limiting factors at the 2-3 nm scale of grain boundaries is recommended, since the FEG-SEM in terms of EDXS resolution can precisely classify only the intergranular junctions and particle boundaries of size $\geq 0.5 \mu \mathrm{m}$ and distinguishing different crystal structures was not possible with the existing setup.

Table 2. FEG-SEM EDXS quantification of different phases in the $2 \mathrm{wt}$. \% Pr-Cu GBD processed recycled HDDR Nd-Fe-B bulk magnets.

\begin{tabular}{|c|c|c|c|c|c|c|c|}
\hline Phases & Nd (at. \%) & $\operatorname{Pr}($ at. \%) & Dy (at. \%) & Fe (at. \%) & $\mathrm{O}($ at. $\%)$ & Al (at. \%) & $\mathrm{Cu}($ at. $\%)$ \\
\hline $\mathrm{Nd}_{2} \mathrm{Fe}_{14} \mathrm{~B}$ & 13.1 & 2.2 & - & 80.7 & - & 1.1 & 2.9 \\
\hline$(\mathrm{Pr}, \mathrm{Nd})_{2} \mathrm{Fe}_{14} \mathrm{~B}$ & 4.2 & 9.3 & - & 85.6 & - & 0.9 & - \\
\hline $\begin{array}{c}\text { (Pr,Nd)-rich Phase } \\
(\mathrm{Pr}, \mathrm{Nd}) \mathrm{O}_{\mathrm{x}} /(\mathrm{Pr}, \mathrm{Nd}) \mathrm{O}_{2}\end{array}$ & 7.5 & 19.5 & - & 1.5 & 71.5 & - & - \\
\hline $\mathrm{Pr}_{2} \mathrm{O}_{3} / \mathrm{Nd}_{2} \mathrm{O}_{3}$ & 10.4 & 15.4 & - & 10.5 & 63.7 & - & - \\
\hline$(\mathrm{Nd}, \mathrm{Pr})_{2} \mathrm{CuO}_{2}$ & 20.1 & 13.4 & 2.1 & 14.8 & 30.9 & - & 18.7 \\
\hline$(\mathrm{Pr}, \mathrm{Nd})_{\mathrm{X}} \mathrm{CuO}_{4}$ & 9.1 & 13.0 & - & 3.0 & 51.4 & - & 23.5 \\
\hline $\mathrm{RE}_{2} \mathrm{CuO}_{2}$ & 23.7 & 16.5 & 3.3 & 10.7 & 32.6 & - & 13.2 \\
\hline
\end{tabular}

* Oxford Instruments INCA 350 EDXS $20 \mathrm{~mm}^{2}$ detector Point ID analysis system at $20 \mathrm{kV}$ and XPP matrix corrections with quantitative error for light elements in standard deviation (S.D) $\sim 0.085$ and for combined elements S.D $\sim 0.055$. Quant and Profile optimization applied for normalized Point ID analysis with $>10 \mathrm{k}$ cps during all individual quantitative measurements. All individual measurements except the last three were repeated twice and average at. $\%$ values are reported in this study.

It is anticipated that the secondary annealing above the $\mathrm{Pr}-\mathrm{Cu}$ binary eutectic point $472{ }^{\circ} \mathrm{C}$ only resulted in re-melting and redistribution of localized $\mathrm{Pr}-\mathrm{Cu}$ phase from the particle and intergranular boundaries. It is speculated based on EDXS results that although $\mathrm{Cu}$ remains segregated within the liquid phase, Pr and Nd switch positions asymmetrically, such that per this matrix facets substitution implies liquid phase becoming richer with $\mathrm{Nd}$ instead of $\mathrm{Pr}$. The melting point of eutectic $\mathrm{Nd}-\mathrm{Cu}$ alloy is $520^{\circ} \mathrm{C}$ [42], indicating limited capillary flow distance and redistribution of Nd-rich species. However, this temperature is effective in releasing the thermal processing strains within the magnets, which subsequently resulted into an improvement of the coercivity as well as the remanent magnetization [22].

The lamellar structure of intergranular phase is rich with $\mathrm{Cu}$ and rare-earth elements illustrated in Figure 3E, corresponds to $\mathrm{RE}_{2} \mathrm{CuO}_{2}$ [60] with brighter contrast, while a darker tone $\mathrm{RE}_{X} \mathrm{CuO}_{4}$ phase (cuprate with long-range magnetic order) was also identified within this extended region [61] as the RE-rich phase was diffused inwards. The bright lamellar ( $\mathrm{Nd}, \mathrm{Pr})_{2} \mathrm{CuO}_{2}$ is widely distributed within 
the $\sim 600 \mu \mathrm{m}$ diffusion zone indicating conversion of the primary $\mathrm{Nd}$-rich phase $\mathrm{NdO}_{\mathrm{X}}$ to $(\mathrm{Pr}, \mathrm{Nd}) \mathrm{O}_{2}$ phase, which is a thermodynamic transformation precipitated by $\mathrm{Cu}$ at the intergranular junctions and the grain boundaries [43]. This region in the extended diffusion zone, shown in and supplementary Figure $\mathrm{S} 1(\mathrm{C})$, illustrates the RE-rich region containing complex cuprates [the darker $(\mathrm{Pr}, \mathrm{Nd}) \mathrm{CuO}_{4}$ and grayish lamellar $(\mathrm{Pr}, \mathrm{Nd})_{2} \mathrm{CuO}_{2}$ phase] are of size $300-500 \mathrm{~nm}$, co-existing with $(\mathrm{Pr}, \mathrm{Nd}) \mathrm{O}_{\mathrm{X}}$ phase. The magnetic exchange effects originating from $(\mathrm{Nd}, \mathrm{Pr}) \mathrm{CuO}_{4}$ at the intergranular regions are out of scope for concurrent study. In the vicinity, $\mathrm{Pr}$ from the melt also partially substitutes $\mathrm{Nd}$ in the hard-ferromagnetic matrix by transforming to $(\mathrm{Pr}, \mathrm{Nd})_{2} \mathrm{Fe}_{14} \mathrm{~B}$ phase [46,58]. Previous literature reported the segregation of $\mathrm{Cu}$ and transition metals $(\mathrm{Fe}, \mathrm{Co})$ at the intergranular phase along the interface with $(\mathrm{Pr}, \mathrm{Nd})_{2} \mathrm{Fe}_{14} \mathrm{~B}$ nanocrystalline grains [58], which apparently is also true for the HDDR Nd-Fe-B system; however, this type of analysis is beyond the scope of utilized FEG-SEM and EDXS technique. The region beyond the diffusion zone shown in Figure $3 \mathrm{~F}$ primarily consisted of microstructure similar to that of the bulk sintered magnet prior to GBDP, with exception of very limited Nd-rich phase redistribution in sparse regions only. This suggests that the overall diffusion depth of eutectic $\mathrm{Pr}-\mathrm{Cu}$ alloys from the surface is limited to $\sim 600 \mu \mathrm{m}$ in the HDDR Nd-Fe-B based bulk magnets, prioritizing the requirement of localized grain boundary engineering instead of surface diffusion treatments.

\subsection{Magfine MF-15P Grain Boundary Diffusion Treatment}

The commercial grade MF-15P type HDDR Nd-Fe-B has been sparsely used in research but has been popular for the bonded magnet applications due to suitable magnetic properties at room temperature and up to $100{ }^{\circ} \mathrm{C}$ [24]. In order to compare the effectiveness of Pr-Cu diffusion treatment, the MFMs were produced with similar SPS and GBD processing conditions. The optimally SPS-ed and annealed MFMs have starting $H_{C i}=968 \mathrm{kA} / \mathrm{m}, B_{r}=1.07 \mathrm{~T}, B H_{\max }=198 \mathrm{~kJ} / \mathrm{m}^{3}$ and $99 \%$ relative density. In this case with MFMs, 10 and $20 \mathrm{wt}$. \% of Pr-Cu alloy ribbons were added to the crucible to achieve optimal diffusion treatment results to compare with GBDP MRs, as shown in Figure 4. The GBDP with 10 wt. \% Pr-Cu alloy ribbons improved the $H_{C i}$ to $1206 \mathrm{kA} / \mathrm{m}$ (at primary diffusion treatment) and $1255 \mathrm{kA} / \mathrm{m}$ (secondary annealing). The $B_{r}$ reduced slightly to $0.96 \mathrm{~T}$ for $4.11 \%$ mass gain $(0.113 \mathrm{~g})$, as plotted in Figure $4 \mathrm{~b}$. Similarly, according to Figure $4 \mathrm{~b}$, the MFM sample diffusion treated with 20 wt. \% Pr-Cu alloy gained mass by $0.171 \mathrm{~g}(6.37 \%)$, which resulted in $H_{C i}$ boosted to $1269 \mathrm{kA} / \mathrm{m}$ (at $900{ }^{\circ} \mathrm{C}$ ) and consequently, after $500{ }^{\circ} \mathrm{C}$ annealing to $1313 \mathrm{kA} / \mathrm{m}$ with $B_{r}=1.04 \mathrm{~T}$. This resistance to demagnetization i.e. coercivity is approx. $35.6 \%$ better than optimally SPS processed MFMs and a modest $11.3 \%$ better than the previously reported [24].

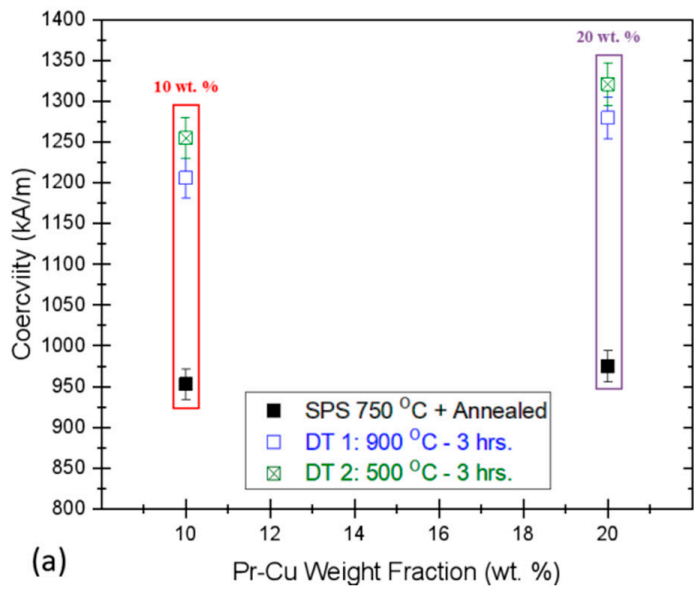

Figure 4. Illustrates the deviations in (a) coercivity $\left(H_{C i}\right)$ and $(\mathbf{b})$ remanence $\left(B_{r}\right)$ with GBD treatment for different wt. $\% \operatorname{Pr}_{68} \mathrm{Cu}_{32}$ alloy ribbons. Plots legend: red $10 \mathrm{wt}$. \% and purple $20 \mathrm{wt}$. $\% \mathrm{Pr}-\mathrm{Cu}$ as the diffusion source on fresh HDDR Nd-Fe-B SPS-ed magnets (MFM). 
Figure 3C-F confirms gradient microstructure of the Pr-Cu GBDP HDD Nd-Fe-B magnet with surface regions experiencing magnetic hardening as compared to the inner segment. The magnetic properties of the bulk HDDR Nd-Fe-B magnets after GBDP with the eutectic Dy-Cu and Pr-Cu alloys are organized in Table 3. The results indicate that although the GBDP of the eutectic alloy ribbons is limited in mass gain and diffusion depth to near surface regions ( $600 \mu \mathrm{m}$ for Pr-Cu alloy) in the HDDR system, the Dy-Cu alloys are comparatively less effective in improving the coercivity as compared to $\mathrm{Pr}-\mathrm{Cu}$ alloys, besides a more significant impact on the magnetization reduction $\left(B_{r}<0.1 \mathrm{~T}\right)$ in case of former type alloys due to the HREEs and unreacted Dy at the boundary interfaces adds up to the reduction in $B_{r}$ as well as $H_{C i}$. Henceforth, the Dy-Cu alloys will always cause reduction in the $B_{r}$ for the diffusing Dy implying that the Dy-Cu alloy ribbons did not achieve adequate liquefaction as the Pr-Cu ribbons under the $900{ }^{\circ} \mathrm{C}$ GBDP conditions, owing to their high eutectic temperature which caused very limited $H_{C i}$ improvement in RMs. The improvement achieved with eutectic $\mathrm{Pr}-\mathrm{Cu}$ alloys is approx. $60 \%$ in $H_{C i}$ as compared to Dy-Cu alloys at $55 \%$ in the recycled HDDR Nd-Fe-B system. This effect of $\mathrm{Pr}-\mathrm{Cu}$ alloys excelling Dy-Cu has been previously identified in the commercial grade sintered magnets treated with same composition of eutectic alloys diffusion processed at $900{ }^{\circ} \mathrm{C}$ for $4 \mathrm{~h}$, suggested the lower melting Pr-Cu alloy registered approx. $240 \mathrm{kA} / \mathrm{m}$ higher $H_{\mathrm{C} i}$ over Dy-Cu alloy, although the latter alloy developed core-shell structures [46]. The secondary annealing is responsible for the relaxation of thermal stresses and reformation of grain facets, such that the grain boundary distribution is more uniform among the grains after the secondary annealing. As a matter of fact, the diffusing Dy-rich species via surface GBDP were found less effective as compared to the HREEs original added to the composition because of unreacted Dy at the interface and inhomogeneous core-shell formation, which in turn increases the coercivity $\mu_{\mathrm{O}} \mathrm{H}_{\mathrm{C}}>2 \mathrm{~T}$ [56]. Similarly, the Pr-Cu alloy ribbons enhanced the $H_{C i}$ without negligible impact on the $B_{r}$ of the fresh MF-15P HDDR Nd-Fe-B system by $25 \%$ over the starting HDDR powder (MFP) and pre-GBDP bulk magnet (MFM) by $36 \%$ approximately. Evidently for the HDDR Nd-Fe-B system, the observed mass gain associated with Dy-Cu alloy is lower for all weight fractions as compared to $\mathrm{Pr}-\mathrm{Cu}$ alloys confirming the thermally controlled concentration gradient effect here. This suggests that the eutectic Dy-Cu system may be more effective for the HDDR Nd-Fe-B powders instead of the bulk magnets subsequently due to rapid and uniform short-range diffusion over loose powder with a high surface area at these GBDP conditions. In case of the HDDR powders, there may not be a requirement to facilitate short-range diffusion from the particle interfaces, so GBDP HDDR powder with Dy-Cu alloys can later be compacted with SPS and annealed as a general suggestion for the future work. A pragmatic recommendation for future research would also be to mill-down the eutectic alloy ribbons to reduce the surface tension associated effects which limit the capillary diffusion and redistribution of RE-rich species under concentration gradients. Another alternative is to uniformly mix the finely milled alloy ribbons with the rare-earth-lean recycled HDDR Nd-Fe-B powder and subsequently sinter them with the SPS at even lower temperatures, such that overall processing steps are considerably reduced. Utilization of hyper-eutectic rare-earth rich alloys instead also has effectively served the purpose in the sintered and hot deformed magnets $[45-47,56,58]$.

Table 3. Magnetic properties of HDDR Nd-Fe-B bulk magnets after Pr-Cu and Dy-Cu GBDP.

\begin{tabular}{|c|c|c|c|c|c|}
\hline & $\begin{array}{l}\text { Diffusion Source Alloy } \\
\text { Weight Fraction }\end{array}$ & Coercivity $\mathrm{H}_{\mathrm{Ci}}(\mathrm{kA} / \mathrm{m})$ & Remanence $B_{r}(T)$ & $\mathrm{BH}_{\max }\left(\mathrm{kJ} / \mathrm{m}^{3}\right)$ & Actual Mass Gain (\%) \\
\hline \multirow{4}{*}{$\begin{array}{c}\text { Dy }_{70} \mathrm{Cu}_{30}+\text { Recycled } \\
\text { Magnet (MR) }\end{array}$} & 0 wt. $\%$ & 1148 & 0.81 & 115 & - \\
\hline & 2 wt. $\%$ & 1250 & 0.74 & 90 & 1.94 \\
\hline & 10 wt. $\%$ & 1256 & 0.78 & 105 & 2.57 \\
\hline & 20 wt. $\%$ & 1287 & 0.77 & 104 & 3.25 \\
\hline \multirow{4}{*}{$\begin{array}{c}\operatorname{Pr}_{68} \mathrm{Cu}_{32}+\text { Recycled } \\
\text { Magnet (MR) }\end{array}$} & 0 wt. $\%$ & 1160 & 0.83 & 120 & - \\
\hline & 2 wt. $\%$ & 1283 & 0.82 & 116 & 2.00 \\
\hline & 10 wt. $\%$ & 1308 & 0.78 & 107 & 3.87 \\
\hline & 20 wt. $\%$ & 1322 & 0.75 & 100 & 4.96 \\
\hline \multirow{3}{*}{$\begin{array}{c}\operatorname{Pr}_{68} \mathrm{Cu}_{32}+\text { Fresh } \\
\text { Magnet (MFM) }\end{array}$} & 0 wt. $\%$ & 969 & 1.07 & 198 & - \\
\hline & 10 wt. $\%$ & 1255 & 0.96 & 127 & 4.11 \\
\hline & 20 wt. $\%$ & 1313 & 1.04 & 190 & 6.37 \\
\hline
\end{tabular}




\section{Conclusions}

The HDDR Nd-Fe-B based bulk magnets were grain boundary diffusion (GBD) treated with the eutectic alloy ribbons of $\mathrm{Pr}-\mathrm{Cu}$ and $\mathrm{Dy}-\mathrm{Cu}$ in the range of $900^{\circ} \mathrm{C}$. The variation in magnetic properties was studied with respect to different weight fractions of $\mathrm{Pr}-\mathrm{Cu}$ and Dy-Cu alloy ribbons placed on top and bottom of the bulk magnets for thermal processing. The GBDP resulted in improvement of the coercivity of the HDDR Nd-Fe-B systems, bulk magnets made from both fresh and recycled materials. The high temperature Dy-Cu eutectic was found less efficient as compared to low melting $\mathrm{Pr}-\mathrm{Cu}$ binary eutectic during the scheme of primary processing at $900{ }^{\circ} \mathrm{C}$ and secondary annealing at $500{ }^{\circ} \mathrm{C}$ resulted in overall improvement $H_{C i}$ by $60 \%$ at $1322 \mathrm{kA} / \mathrm{m}$ as compared to $830 \mathrm{kA} / \mathrm{m}$ for the recycled powder. Correspondingly, the fresh MF-15P HDDR Nd-Fe-B based bulk magnets gained up to $36 \%$ improvement in $H_{C i}$ without a substantial decrease in $B_{r}$, proving the suitability of GBDP with binary eutectic alloys. Therefore, the transport of liquid phase from the surface to the particle boundaries is postulated to occur under the effect of concentration gradient which is controlled by temperature and interparticle phase chemistry, whereas further from the particles to the grain boundaries is activated by capillary transport. On the contrary, the mass gain was lower than total diffusing species. It was further observed with SEM analysis that the diffusion treatment is limited in achieving thorough surface penetration, primarily because of reduced capillary forces from high weight fraction of molten species creating surface tension and lack of excessive particle boundaries in fully dense magnets. The matrix adjacent to the diffusion zone up to $\sim 600 \mu \mathrm{m}$ constitutes of $(\mathrm{Pr}, \mathrm{Nd})_{2} \mathrm{Fe}_{14} \mathrm{~B}$ nanocrystalline grains with RE-rich $(\mathrm{Pr}, \mathrm{Nd}) \mathrm{O}_{2}$ and the secondary phases: lamellar $\mathrm{Nd}_{2} \mathrm{CuO}_{2}$ and $(\mathrm{Nd}, \mathrm{Pr}) \mathrm{CuO}_{4}$ at the intergranular regions. The region beyond the diffusion zone is similar to the bulk magnets prior to the GBD treatment. Nonetheless, the retention of magnetization $\left(B_{r}\right)$ after GBDP indicate limited surface diffusivity for the mass gain is still effective in revitalizing the coercivity and the bulk magnets have gradient microstructure with magnetic hardening of the surface regions. Convincingly, this report also suggests that eutectic $\mathrm{Dy}_{70} \mathrm{Cu}_{30}$ is not an optimal alloy for GBDP of the HDDR Nd-Fe-B bulk magnets because of the requirement for very high processing temperatures to activate the mass diffusion. The effectiveness of eutectic Dy-Cu alloy's is substantially slower than Pr-Cu alloys based on mass and coercivity gain, thus limiting its GBDP applicability to HDDR Nd-Fe-B powders only, since processing above $900^{\circ} \mathrm{C}$ may deteriorate the magnetic properties due to unnecessary abnormal grain coarsening.

Supplementary Materials: The following are available online at http://www.mdpi.com/1996-1944/13/16/3528/s1, Figure S1: Supplementary backscattered electron microscopy images of (A) diffusion zone at 10,000 $\times$ magnification showing the particle boundary on the right side and $\mathrm{Nd}$-rich pool (lamellar morphology of $\mathrm{NdO}_{\mathrm{X}}$ composition) and in the vicinity $(\mathrm{Pr}, \mathrm{Nd})_{2} \mathrm{Fe}_{14} \mathrm{~B}$ phases, $(\mathbf{B})$ alternate higher magnification $(20 \mathrm{kX})$ image of the diffusion zone with solidified liquid phase $(\mathrm{Pr}, \mathrm{Nd}) \mathrm{O}_{\mathrm{X}}$ diffused with the addition of $2 \mathrm{wt}$. $\% \mathrm{Pr}-\mathrm{Cu}$ alloy and the presence of Pr-containing matrix phase and lamellar $\mathrm{NdO}_{x}$ phase (bright contrast), (C) high magnification $(30,000 \times)$ image of diffusion zone extended beyond $\sim 250 \mu \mathrm{m}$ and indicating presence of complex cuprates in the thick intergranular phase, and (D) $20 \mathrm{kX}$ magnification of the extended zone with non-uniform distribution of liquid phase along the hard matrix phase.

Author Contributions: Conceptualization, A.I.; methodology, A.I.; software, A.I.; validation, A.I. and M.A.; formal analysis, A.I.; investigation, A.I.; resources, M.A., R.S. and A.W.; data curation, A.I.; writing-original draft preparation, A.I.; writing-review and editing, A.I., M.A. and F.P.; visualization, A.I.; supervision, S.K., A.W., K.Ž.R. and F.P.; project administration, K.Ž.R., S.K. and A.W.; and funding acquisition, S.K., A.W. and K.Ž.R. All authors have read and agreed to the published version of the manuscript.

Funding: The study leading to these results received funding from the European Community's Horizon 2020 Program ([H2020/2014-2019]) under Grant Agreement No. 674973 (MSCA-ETN DEMETER). Project website: http://etn-demeter.eu/. Programme from Slovenian Research Agency P2-0084 and the project L2-9213 are also gratefully acknowledged for partial funding. This publication reflects only the authors' research findings, which are targeted to contribute to the betterment of the global community.

Acknowledgments: The authors duly acknowledge the Center for Electron Microscopy \& Microanalysis (CEMM) for supporting the scanning electron microscopy analysis at the Jožef Stefan Institute, Slovenia.

Conflicts of Interest: The authors declare that this research was performed in the absence of any commercial or financial relationships that could be interpreted as a potential conflict of interest. 


\section{References}

1. Balasubramanian, B.; Mukherjee, P.; Skomski, R.; Manchanda, P.; Das, B.; Sellmyer, D.J. Magnetic nanostructuring and overcoming Brown's paradox to realize extraordinary high-temperature energy products. Sci. Rep. 2014, 4, 6265. [CrossRef] [PubMed]

2. Barbosa, L.P.; Takiishi, H.; Faria, R.N. The effect of cobalt content on the microstructure of $\mathrm{Pr}-\mathrm{Fe}-\mathrm{Co}-\mathrm{B}-\mathrm{Nb}$ alloys and magnetic properties of HDDR magnets. J. Magn. Magn. Mater. 2004, 268, 132-139. [CrossRef]

3. Binnemans, K.; Jones, P.T.; Müller, T.; Yurramendi, L. Rare Earths and the Balance Problem: How to Deal with Changing Markets? J. Sustain. Metall. 2018, 4, 126-146. [CrossRef]

4. Cha, H.-R.; Yu, J.-H.; Baek, Y.-K.; Kwon, H.-W.; Kim, Y.-D.; Lee, J.-G. The Influence of Dehydrogenation Speed on the Microstructure and Magnetic Properties of Nd-Fe-B Magnets Prepared by HDDR Process. J. Magn. 2014, 19, 49-54. [CrossRef]

5. Gang, S.; Lianxi, H.; Erde, W. Preparation, microstructure, and magnetic properties of a nanocrystalline Nd12Fe82B6 alloy by HDDR combined with mechanical milling. J. Magn. Magn. Mater. 2006, 301, 319-324. [CrossRef]

6. Gopalan, R.; Sepehri-Amin, H.; Suresh, K.; Ohkubo, T.; Hono, K.; Nishiuchi, T.; Nozawa, N.; Hirosawa, S. Anisotropic Nd-Fe-B nanocrystalline magnets processed by spark plasma sintering and in situ hot pressing of hydrogenation-decomposition-desorption-recombination powder. Scr. Mater. 2009, 61, 978-981. [CrossRef]

7. Gutfleisch, O. Controling the properties of high energy density permanent magnetic materials by different processing routes. J. Phys. Appl. Phys. 2000, 33, R157-R172. [CrossRef]

8. Güth, K.; Lyubina, J.; Gebel, B.; Schultz, L.; Gutfleisch, O. Ultra-fine grained Nd-Fe-B by high pressure reactive milling and desorption. J. Magn. Magn. Mater. 2012, 324, 2731-2735. [CrossRef]

9. Han, J.; Liu, S.; Wang, C.; Chen, H.; Du, H.; Yang, Y. Effects of the conventional HDDR process and the additions of $\mathrm{Co}$ and $\mathrm{Zr}$ on anisotropy of HDDR Pr-Fe-B-type magnetic materials. J. Magn. Magn. Mater. 2009, 321, 1331-1334. [CrossRef]

10. Hono, K.; Sepehri-Amin, H. Strategy for high-coercivity Nd-Fe-B magnets. Scr. Mater. 2012, 67, 530-535. [CrossRef]

11. Horikawa, T.; Matsuura, M.; Sugimoto, S.; Yamazaki, M.; Mishima, C. Hydrogen Pressure and Temperature Dependence of the Disproportionated State and Magnetic Anisotropy in the $d$-HDDR Process of Nd-Fe-B-Ga-Nb Powders. IEEE Trans. Magn. 2015, 51, 1-4. [CrossRef]

12. Ikram, A.; Awais, M.; Sheridan, R.; Walton, A.; Kobe, S.; Pušavec, F.; Rožman, K. Žužek Spark Plasma Sintering as an Effective Texturing Tool for Reprocessing Recycled HDDR Nd-Fe-B Magnets with Lossless Coercivity. Metals 2020, 10, 418. [CrossRef]

13. Ikram, A.; Mehmood, F.; Sheridan, R.S.; Awais, M.; Walton, A.; Eldosouky, A.; Sturm, S.; Kobe, S.; Rozman, K.Z. Particle size dependent sinterability and magnetic properties of recycled HDDR Nd-Fe-B powders consolidated with spark plasma sintering. J. Rare Earths 2020, 38, 90-99. [CrossRef]

14. Ikram, A.; Mehmood, M.F.; Podlogar, M.; Eldosouky, A.; Sheridan, R.; Awais, M.; Walton, A.; Kržmanc, M.M.; Tomse, T.; Kobe, S.; et al. The sintering mechanism of fully dense and highly coercive Nd-Fe-B magnets from the recycled HDDR powders reprocessed by spark plasma sintering. J. Alloy. Compd. 2019, 774, 1195-1206. [CrossRef]

15. Ikram, A.; Mehmood, M.F.; Samardžija, Z.; Sheridan, R.; Awais, M.; Walton, A.; Šturm, S.; Kobe, S.; Rožman, K. Žužek Coercivity Increase of the Recycled HDDR Nd-Fe-B Powders Doped with DyF3 and Processed via Spark Plasma Sintering \& the Effect of Thermal Treatments. Materials 2019, 12, 1498. [CrossRef]

16. Kim, T.-H.; An, B.-S.; Cha, H.-R.; Lee, J.; Kwon, H.; Yang, C.-W. Effect of desorption and recombination on texture development in hydrogenation-disproportionation-desorption-recombination processed $\mathrm{Nd}-\mathrm{Fe}-\mathrm{B}$ magnets. J. Alloy. Compd. 2016, 672, 582-589. [CrossRef]

17. Kim, T.-H.; Lee, S.-R.; Lee, M.-W.; Jang, T.-S.; Kim, J.W.; Kim, Y.D.; Kim, H.-J. Dependence of magnetic, phase-transformation and microstructural characteristics on the $\mathrm{Cu}$ content of $\mathrm{Nd}-\mathrm{Fe}-\mathrm{B}$ sintered magnet. Acta Mater. 2014, 66, 12-21. [CrossRef]

18. Kimiabeigi, M.; Sheridan, R.; Widmer, J.D.; Walton, A.; Farr, M.; Scholes, B.; Harris, I. Production and Application of HPMS Recycled Bonded Permanent Magnets for a Traction Motor Application. IEEE Trans. Ind. Electron. 2017, 65, 3795-3804. [CrossRef] 
19. Kwon, H.; Lee, J.; Yu, J.H. Origin of radical coercivity reduction in fine Nd-Fe-B-type hydrogenation, disproportionation, desorption, recombination particles and its recovery. J. Appl. Phys. 2014, 115, 17. [CrossRef]

20. Li, C.; Yue, M.; Liu, W.; Zuo, T.; Yi, X.; Chen, J.; Zhou, Z.; Wu, Y. Recycling of scrap sintered Nd-Fe-B magnets as anisotropic bonded magnets via hydrogen decrepitation process. J. Mater. Cycles Waste Manag. 2014, 17, 547-552. [CrossRef]

21. Li, L.; Jones, K.; Sales, B.; Pries, J.; Nlebedim, I.; Jin, K.; Bei, H.; Post, B.K.; Kesler, M.S.; Rios, O.; et al. Fabrication of highly dense isotropic Nd-Fe-B nylon bonded magnets via extrusion-based additive manufacturing. Addit. Manuf. 2018, 21, 495-500. [CrossRef]

22. Li, W.F.; Ohkubo, T.; Hono, K.; Nishiuchi, T.; Hirosawa, S. Coercivity mechanism of hydrogenation disproportionation desorption recombination processed Nd-Fe-B based magnets. Appl. Phys. Lett. 2008, 93, 052505. [CrossRef]

23. Li, W.F.; Ohkubo, T.; Hono, K.; Nishiuchi, T.; Hirosawa, S. The role of grain boundaries in the coercivity of hydrogenation disproportionation desorption recombination processed Nd-Fe-B powders. J. Appl. Phys. 2009, 105, 07A706. [CrossRef]

24. Liu, L.; Sepehri-Amin, H.; Ohkubo, T.; Yano, M.; Kato, A.; Sakuma, N.; Shoji, T.; Hono, K. Coercivity enhancement of hot-deformed $\mathrm{Nd}-\mathrm{Fe}-\mathrm{B}$ magnets by the eutectic grain boundary diffusion process using $\mathrm{Nd}$ 62 Dy 20 Al 18 alloy. Scr. Mater. 2017, 129, 44-47. [CrossRef]

25. Liu, L.; Sepehri-Amin, H.; Ohkubo, T.; Yano, M.; Kato, A.; Shoji, T.; Hono, K. Coercivity enhancement of hot-deformed Nd-Fe-B magnets by the eutectic grain boundary diffusion process. J. Alloy. Compd. 2016, 666, 432-439. [CrossRef]

26. Liu, M.; Jin, X.-C.; Gao, R.-W. Effects of intergranular phase and structure defect on the coercivity for the HDDR Nd-Fe-B bonded magnet. J. At. Mol. Sci. 2012, 3, 218-226. [CrossRef]

27. Liu, M.; Sun, Y.; Han, G.; Yang, W.; Gao, R. Dependence of anisotropy and coercivity on microstructure in HDDR Nd-Fe-B magnet. J. Alloy. Compd. 2009, 478, 303-307. [CrossRef]

28. Lixandru, A.; Poenaru, I.; Güth, K.; Gauß, R.; Gutfleisch, O. A systematic study of HDDR processing conditions for the recycling of end-of-life Nd-Fe-B magnets. J. Alloy. Compd. 2017, 724, 51-61. [CrossRef]

29. Luo, J.; De Rango, P.; Fruchart, D.; Mei, J.; Zhou, L. Hydrogen absorption and desorption characteristics of high coercivity $\mathrm{NdDyFeCoNbCuB}$ sintered magnet. I. Low temperature hydrogen decrepitation treatments. J. Alloy. Compd. 2011, 509, 4252-4259. [CrossRef]

30. Morimoto, K.; Kaneko, S.; Katayama, N.; Shigeoka, K. Effect of substituting Pr for Nd on magnetic properties of Nd-Fe-B HDDR powder. J. Alloy. Compd. 2016, 666, 118-121. [CrossRef]

31. Morimoto, K.; Katayama, N.; Akamine, H.; Itakura, M. Coercivity enhancement of anisotropic Dy-free $\mathrm{Nd}-\mathrm{Fe}-\mathrm{B}$ powders by conventional HDDR process. J. Magn. Magn. Mater. 2012, 324, 3723-3726. [CrossRef]

32. Nakamura, H. The current and future status of rare earth permanent magnets. Scr. Mater. 2018, 154, $273-276$. [CrossRef]

33. Nakamura, M.; Matsuura, M.; Tezuka, N.; Sugimoto, S.; Une, Y.; Kubo, H.; Sagawa, M. Preparation of ultrafine jet-milled powders for Nd-Fe-B sintered magnets using hydrogenation-disproportionation-desorption-recombination and hydrogen decrepitation processes. Appl. Phys. Lett. 2013, 103, 22404. [CrossRef]

34. Nakamura, M.; Matsuura, M.; Tezuka, N.; Sugimoto, S.; Une, Y.; Kubo, H.; Sagawa, M. Effects of Hydrogenation-Disproportionation-Desorption-Recombination Processing Parameters on the Particle Size of Ultrafine Jet-Milled Nd-Fe-B Powders. Mater. Trans. 2015, 56, 129-134. [CrossRef]

35. Pal, S.; Güth, K.; Woodcock, T.; Schultz, L.; Gutfleisch, O. Properties of isolated single crystalline and textured polycrystalline nano/sub-micrometre Nd2Fe14B particles obtained from milling of HDDR powder. J. Phys. D Appl. Phys. 2013, 46, 375004. [CrossRef]

36. Périgo, E.A.; Da Silva, S.C.; Martins, R.V.; Takiishi, H.; Landgraf, F.J.G. Properties of hydrogenation-disproportionation-desorption-recombination NdFeB powders prepared from recycled sintered magnets. J. Appl. Phys. 2012, 111, 7. [CrossRef]

37. Reimer, M.; Schenk-Mathes, H.; Hoffmann, M.; Elwert, T. Recycling Decisions in 2020, 2030, and 2040-When Can Substantial NdFeB Extraction be Expected in the EU? Metals 2018, 8, 867. [CrossRef] 
38. Seelam, U.; Liu, L.; Akiya, T.; Sepehri-Amin, H.; Ohkubo, T.; Sakuma, N.; Yano, M.; Kato, A.; Hono, K. Coercivity of the $\mathrm{Nd}-\mathrm{Fe}-\mathrm{B}$ hot-deformed magnets diffusion-processed with low melting temperature glass forming alloys. J. Magn. Magn. Mater. 2016, 412, 234-242. [CrossRef]

39. Seelam, U.; Ohkubo, T.; Abe, T.; Hirosawa, S.; Hono, K. Faceted shell structure in grain boundary diffusion-processed sintered Nd-Fe-B magnets. J. Alloy. Compd. 2014, 617, 884-892. [CrossRef]

40. Sepehri-Amin, H.; Li, W.; Ohkubo, T.; Nishiuchi, T.; Hirosawa, S.; Hono, K. Effect of Ga addition on the microstructure and magnetic properties of hydrogenation-disproportionation-desorption-recombination processed Nd-Fe-B powder. Acta Mater. 2010, 58, 1309-1316. [CrossRef]

41. Sepehri-Amin, H.; Liu, L.; Ohkubo, T.; Yano, M.; Shoji, T.; Kato, A.; Schrefl, T.; Hono, K. Microstructure and temperature dependent of coercivity of hot-deformed Nd-Fe-B magnets diffusion processed with $\mathrm{Pr}-\mathrm{Cu}$ alloy. Acta Mater. 2015, 99, 297-306. [CrossRef]

42. Sepehri-Amin, H.; Ohkubo, T.; Nishiuchi, T.; Hirosawa, S.; Hono, K. Coercivity enhancement of hydrogenation-disproportionation-desorption-recombination processed $\mathrm{Nd}-\mathrm{Fe}-\mathrm{B}$ powders by the diffusion of Nd-Cu eutectic alloys. Scr. Mater. 2010, 63, 1124-1127. [CrossRef]

43. Sheridan, R.; Harris, I.; Walton, A. The development of microstructure during hydrogenationdisproportionation-desorption-recombination treatment of sintered neodymium-iron-boron-type magnets. J. Magn. Magn. Mater. 2016, 401, 455-462. [CrossRef]

44. Sheridan, R.; Sillitoe, R.; Zakotnik, M.; Harris, I.; Williams, A. Anisotropic powder from sintered NdFeB magnets by the HDDR processing route. J. Magn. Magn. Mater. 2012, 324, 63-67. [CrossRef]

45. Sheridan, R.; Williams, A.; Harris, I.; Walton, A. Improved HDDR processing route for production of anisotropic powder from sintered NdFeB type magnets. J. Magn. Magn. Mater. 2014, 350, 114-118. [CrossRef]

46. Song, T.; Tang, X.; Yin, W.; Chen, R.; Yan, A. Coercivity enhancement of hot-pressed magnet prepared by HDDR Nd-Fe-B powders using Pr-Cu eutectic alloys diffusion. J. Magn. Magn. Mater. 2019, 471, 105-109. [CrossRef]

47. Sugimoto, S. Current status and recent topics of rare-earth permanent magnets. J. Phys. D Appl. Phys. 2011, 44, 64001. [CrossRef]

48. Suresh, K.; Ohkubo, T.; Takahashi, Y.; Oh-Ishi, K.; Gopalan, R.; Hono, K.; Nishiuchi, T.; Nozawa, N.; Hirosawa, S. Consolidation of hydrogenation-disproportionation-desorption-recombination processed Nd-Fe-B magnets by spark plasma sintering. J. Magn. Magn. Mater. 2009, 321, 3681-3686. [CrossRef]

49. Szymanski, M.; Michalski, B.; Leonowicz, M.; Miazga, Z. Structure and Properties of Nd-Fe-B Alloy Subjected to HDDR Process. Arch. Met. Mater. 2016, 61, 217-220. [CrossRef]

50. Takagi, K.; Akada, M.; Soda, R.; Ozaki, K. Preparation of Nd-Fe-B sintered magnets from HDDR-processed powder. J. Magn. Magn. Mater. 2015, 393, 461-466. [CrossRef]

51. Tang, M.; Bao, X.; Lu, K.; Sun, L.; Li, J.; Gao, X. Boundary structure modification and magnetic properties enhancement of Nd-Fe-B sintered magnets by diffusing (PrDy)-Cu alloy. Scr. Mater. 2016, 117, 60-63. [CrossRef]

52. Walton, A.; Yi, H.; Rowson, N.; Speight, J.; Mann, V.; Sheridan, R.; Bradshaw, A.; Harris, I.; Williams, A. The use of hydrogen to separate and recycle neodymium-iron-boron-type magnets from electronic waste. J. Clean. Prod. 2015, 104, 236-241. [CrossRef]

53. Wan, F.; Han, J.; Zhang, Y.; Wang, C.; Liu, S.; Yang, J.; Yang, Y.; Sun, A.; Yang, F.; Song, R. Coercivity enhancement in HDDR near-stoichiometric ternary Nd-Fe-B powders. J. Magn. Magn. Mater. 2014, 360, 48-51. [CrossRef]

54. Weber, C.; Haule, K.; Kotliar, G. Strength of correlations in electron- and hole-doped cuprates. Nat. Phys. 2010, 6, 574-578. [CrossRef]

55. Wilson, S.D.; Li, S.; Dai, P.; Bao, W.; Chung, J.-H.; Kang, H.J.; Lee, S.-H.; Komiya, S.; Ando, Y.; $\mathrm{Si}, \mathrm{Q}$. Evolution of low-energy spin dynamics in the electron-doped high-transition-temperature superconductorPr0.88LaCe0.12CuO4- $\delta$. Phys. Rev. B 2006, 74, 144514. [CrossRef]

56. Yamazaki, M.; Mishima, C.; Matsuura, M.; Tezuka, N.; Sugimoto, S.; Horikawa, T. Effect of hydrogenation disproportionation conditions on magnetic anisotropy in Nd-Fe-B powder prepared by dynamic hydrogenation disproportionation desorption recombination. AIP Adv. 2017, 7, 56220. [CrossRef]

57. Zakotnik, M.; Harris, I.; Williams, A. Possible methods of recycling NdFeB-type sintered magnets using the HD/degassing process. J. Alloy. Compd. 2008, 450, 525-531. [CrossRef] 
58. Zakotnik, M.; Harris, I.; Williams, A. Multiple recycling of NdFeB-type sintered magnets. J. Alloy. Compd. 2009, 469, 314-321. [CrossRef]

59. Zhang, Y.; Ma, T.; Liu, X.; Liu, P.; Jin, J.; Zou, J.; Yan, M. Coercivity enhancement of Nd-Fe-B sintered magnets with intergranular adding (Pr, Dy, Cu)-Hx powders. J. Magn. Magn. Mater. 2016, 399, 159-163. [CrossRef]

60. Zhao, G.P.; Wang, X.L. Nucleation, pinning, and coercivity in magnetic nanosystems: An analytical micromagnetic approach. Phys. Rev. B 2006, 74, 012409. [CrossRef]

61. Zheng, B.; Zhao, S. Investigation on mechanism of magnetization reversal for nanocrystalline Pr-Fe-B permanent magnets by micromagnetic finite element methods. J. Rare Earths 2009, 27, 145-149. [CrossRef]

(C) 2020 by the authors. Licensee MDPI, Basel, Switzerland. This article is an open access article distributed under the terms and conditions of the Creative Commons Attribution (CC BY) license (http://creativecommons.org/licenses/by/4.0/). 